\title{
Preparation and Characterisation of Crosslinked Natural Rubber (SMR CV 60) and Epoxidised Natural Rubber (ENR-50) Blends
}

\author{
M. SASITARAN ${ }^{1}$, S. MANROSHAN ${ }^{2}$, C.S. LIM $^{3}$, B. N. KRISHNA VENI ${ }^{2}$, S.K. ONG ${ }^{4}$ \\ AND R. GUNASUNDERI ${ }^{1}$
}

\begin{abstract}
In this study, the influence of di(tert-butylperoxyisopropyl)benzene (DTBPIB) on the properties of natural rubber (NR) blend with epoxidized natural rubber (ENR) was determined. Fourier transform infrared spectroscopy with attenuated total reflectance analysis and gel content confirmed crosslinking occurred in the rubber blends in the presence of peroxide DTBPIB percentage. Studies including tensile properties, dynamic mechanical properties, thermogravimetric analysis (TGA) and water absorptivity showed the changes in properties of the crosslinked NR/ENR blends. Tensile properties analysis disclosed the improvements in the modulus at 300\% elongation and tensile strength with increasing NR ratios. Dynamic mechanical analysis revealed the blends to be incompatible and immiscible, with ENR showing a more viscous behaviour compared to the polymer blends. Thermal properties improved by blending NR with ENR as the onset temperature of NR/ENR: $50 / 50$ was higher than pure NR by approximately $10^{\circ} \mathrm{C}$ and ENR by approximately $2^{\circ} \mathrm{C}$. Water absorptivity experiment revealed a two-fold reduction in the presence of crosslinking for all blend ratios.
\end{abstract}

Key words: Natural rubber; epoxidized natural rubber; polymer blend; peroxide crosslinking agent

The advancement in polymer research has brought about the idea of blending polymers. Blending is a process of mixing two or more polymers creating a product which has the combined properties of the individual polymers (Notario, Pinto \& Rodriguez-Perez 2016; Ramesh 2016). Looking at this, many researchers have diverged their interest from developing novel polymeric compounds through synthesis to blending. Hence, number of studies have been conducted in recent years on blending various polymers which includes rubber-rubber blend, plastic-plastic blend and rubber-plastic blend (Vinod, Varghese \& Kuriakose 2002; Arroyo et al. 2007; Wan Yunus et al. 2013; Notario, Pinto \& RodriguezPerez 2016; Ramesh, 2016). Improvement in thermal, physical and mechanical properties are demonstrated by altering the composition and formulation of blends (Park 2001; De et al. 2013; Díaz, Katsarava \& Puiggalí 2014; Ramesh 2016). By blending, the technical and economic difficulties faced during the synthesis of new homogenous polymers are

\footnotetext{
${ }^{1}$ School of Distance Education, Universiti Sains Malaysia, 11800 Pulau Pinang, Malaysia

${ }^{2}$ Rubber Research Institute of Malaysia, Malaysian Rubber Board, 47000 Sg. Buloh, Malaysia

${ }^{3}$ School of Pharmacy, International Medical University, 57000 Bukit Jalil, Malaysia

${ }^{4}$ Universiti Kuala Lumpur, Malaysian Institute of Chemical and Bioengineering Technology, 78000 Alor Gajah, Melaka, Malaysia

*Corresponding author (e-mail: manroshan@lgm.gov.my)
} 
avoided as this process is more cost effective and time-saving (Arayapranee \& Rempel 2007). Therefore, polymer blending has been recognized as the most promising method to generate new material with tailored individual properties (Ulbricht 2006; Mitragotri \& Lahann 2009).

Malaysia is one of the leading producers of natural rubber (NR). Natural rubber is classified as an elastomer due to the presence of the polyisoprene backbone (Vinod, Varghese \& Kuriakose 2002; Khimi \& Pickering 2015). NR has been widely used in various applications due to its outstanding properties such as high tensile strength, resilience, toughness and good processing characteristic (Gurunathan, Mohanty \& Nayak 2015; Pal \& Panwar 2017). However, there are some limitations to NR properties which includes hardness, modulus, and abrasion resistance that need to be improved for it to be utilized in some specific application (Gurunathan, Mohanty \& Nayak 2015). Moreover, degradation by heat and ozone, high gas permeability and low oil resistance of NR have limited its applications (Wang et al. 2016). Studies reported that blending NR with ENR can be an effective solution to improve the properties for being used in widespread applications (Arroyo et al. 2007; Gurunathan, Mohanty \& Nayak 2015; Wang et al. 2016; Pal \& Panwar 2017).

ENR is produced by modifying NR via epoxidation where the epoxy rings are introduced on the NR backbone and at the same time reduces the number of double bonds (Arroyo et al. 2007). The polarity of the modified polymer depends on the epoxidation level. ENR has been reported to be compatible with other polar polymers (Varghese, KargerKocsis \& Gatos, 2003; Guo et al. 2004;
Rajasekar et al. 2009). ENR has been known since 1992 and is commercially available since the past decade. Currently, Malaysian Rubber Board is producing two grades of ENR (i.e. ENR 25 and ENR 50) with the trade name EKOPRENA. ENR 50 is chemically modified from 1,4-polyisoprene rubber and has some distinct properties such as low air permeability, oil resistance, and lower wet grip compared to synthetic rubber (Vinod, Varghese \& Kuriakose 2002; Gurunathan, Mohanty \& Nayak 2015). Thus, blending NR with ENR is bearing interest to improve stiffness, processibility, resilience and minimizing the damping property of polymers (Imbernon \& Norvez 2016). However, polymer blending has its drawbacks as well. Blending immiscible polymers can result in phase separation of the product, which requires a additional component as a mediator, such as a crosslinking agent to facilitate an interaction between the phases (Ismail, Nordin, 2002; Imbernon \& Norvez 2016).

Crosslinking agents react with polymers either by physical and/or chemical means (Benbettaïeb et al. 2016). The incorporation of a crosslinking agent in polymer blending forms three-dimensional network by generating crosslinks, branching \& extension of the chains (Pedernera \& Sarmoria 1999). Thus, the application of a crosslinking agent in NR blends with ENR might improve strength, stiffness and thermal stability of NR and/or ENR besides restricting water absorptivity of the blend. It is, therefore, the present work aims is to study the blending of Standard Malaysian Rubber (SMR CV 60) with ENR 50, with DTBPIB acting as the crosslinking agent. The resulting blends were characterized for the functional groups, crosslinking degree, tensile properties, thermal stability and water absorptivity. 


\section{EXPERIMENTAL}

\section{Materials}

Malaysian Rubber Board supplied NR grade SMR CV 60 [Mooney viscosity, ML(1+4) $\left.100^{\circ} \mathrm{C}=60\right]$ and $\mathrm{ENR}(50$ mole $\%$ epoxidation $)$. The crosslinking agent, DTBPIB, trade name Luperox ${ }^{\circledR}$ F40 (Figure 1) was purchased from Sigma-Aldrich Chemicals, England, whereas Xylene (analytical grade) was obtained from HmbG, Chemicals, Germany.

\section{METHODOLOGY}

\section{Sample Preparation}

Blending process was initiated by masticating $20 \mathrm{~g}$ of NR using Thermo Haake Polydrive internal mixer, operating at a temperature of $60^{\circ} \mathrm{C}$ with the rotor speed of 50 rotations per minute (rpm) for $2 \mathrm{~min}$. After masticating the NR, $20 \mathrm{~g}$ of ENR 50 was admixed into the mixing chamber. Blending was continued for another 2 min to form NR/ENR: 50/50 blend. The crosslinking agent (DTBPIB) was fixed at $5 \mathrm{phr}$ (parts per hundred rubber). Lastly, DTBPIB was added, and mixing was continued for another additional $6 \mathrm{~min}$. The blends were moulded using compression moulding with a mould of dimension $100 \mathrm{~mm} \times 100 \mathrm{~mm} \times 1 \mathrm{~mm}$, a pressure of $150 \mathrm{~kg} / \mathrm{cm}^{2}$ and cured at $160^{\circ} \mathrm{C}$ for $10 \mathrm{~min}$. The crosslinking temperature used was based on investigations done on peroxides (Thitithammawong, Nakason, Sahakaro \& Noordermeer 2007; Thitithammawong, Nakason, Sahakaro \& Noordermeer 2007). Cooling was carried out using a cold press at $30^{\circ} \mathrm{C}$ for $10 \mathrm{~min}$. Other NR/ENR blends were prepared by changing the mass ratio of NR to ENR to achieve blend ratio of $0 / 100,25 / 75$, $75 / 25$ and $100 / 0 \%$ by weight. Similarly, the above NR/ENR blends were also prepared without DTBPIB.

\section{Determination of Functional Groups}

Fourier transform infrared spectroscopy with attenuated total reflectance analysis (FTIRATR) was carried out using a Perkin Elmer Spectrum 1000 series spectrophotometer. Thin films of all NR/ENR blend ratios with and without DTBPIB were analysed. The infrared spectra of the samples were recorded in the frequency range of $600 \mathrm{~cm}^{-1}$ to $4000 \mathrm{~cm}^{-1}$.

\section{Determination of Crosslinking Degree}

Gel content analysis was used to determine the crosslinking degree of NR/ENR blends with and without DTBPIB. The thin films of all blend ratios were cut into tiny pieces weighing approximately $0.5 \mathrm{~g}$ each and packed in mesh pockets, pre-weighed and labelled. The weight of the mesh pockets with the samples was recorded and the samples were refluxed using xylene in a soxhlet extractor for $24 \mathrm{~h}$. After 24 $\mathrm{h}$ the meshes were removed from the roundbottom flask and dried to a constant weight in an oven at $60^{\circ} \mathrm{C}$. The weight of samples after extraction was recorded and the percentage gel content was calculated using Equation 1:

Gel content $(\%)=\frac{A}{B} \times 100$

Where, $A$ is the weight of the sample after extraction and $B$ is the initial weight of the sample.<smiles>CC(C)(C)OOC(C)(C)c1ccc(C(C)(C)OOC(C)(C)C)cc1</smiles>

Scheme 1. The chemical structure of Luperox ${ }^{\circledR}$ F40 (Mammadov et al. 2012). 


\section{Determination of Tensile Properties}

Tensile test on NR/ENR blends was carried out according to ASTM D638M-98 with a crosshead speed of $50 \mathrm{~mm} / \mathrm{min}$ and a static load cell of 100 $\mathrm{kN}$ using an Instron 4302 series IX, Universal Testing Machine. Each sample's width and thickness were measured prior to testing. The mean value of at least five specimens for each sample was reported.

\section{Determination of Thermal Stability}

The thermal stability of the blends was studied using two techniques, namely: dynamic mechanical analysis and thermogravimetric analysis. For dynamic mechanical analysis, the samples were cut into a rectangular shape (10 $\mathrm{mm} \times 40 \mathrm{~mm} \times 1 \mathrm{~mm})$ and placed in the rotating measuring head of a Mettler Toledo DMA 1 analyser under tension mode with an oscillating frequency of $1 \mathrm{~Hz}$. The dynamic storage modulus (E'), loss modulus (E") and mechanical loss factor $(\tan \delta)$ were recorded in the temperature range of $-100^{\circ} \mathrm{C}$ to $60^{\circ} \mathrm{C}$ at the heating rate of $5^{\circ} \mathrm{C} / \mathrm{min}$. Whereas, thermal decomposition of NR/ENR blends were studied using a Perkin Elmer TGA 7 analyser. The samples were heated from $30^{\circ} \mathrm{C}$ to $800^{\circ} \mathrm{C}$ at a rate of $20^{\circ} \mathrm{C} / \mathrm{min}$ under a nitrogen atmosphere with nitrogen flow rate of $20 \mathrm{ml} / \mathrm{min}$. The onset and maximum degradation temperatures were recorded and plotted as a function of time.

\section{Determination of Water Absorptivity}

The water absorptivity of NR/ENR samples with and without DTBPIB was measured by first cutting the samples to the nearest $1 \mathrm{~g}$ and immersing them in distilled water maintained at room temperature for $840 \mathrm{~h}$ (35 days). The samples from each blend ratio were removed from the distilled water, gently blotted to dry with tissue paper to remove the excess water present on the surface of the samples. The weight of the samples was recorded and dried to constant weight in an oven at a temperature of $60^{\circ} \mathrm{C}$ for $24 \mathrm{~h}$. The percentage of water absorption was calculated using Equation 2:

Water absorptivity $(\%)=\frac{m_{2}-n_{1}}{m^{1}} \times 100$

where, $m_{2}$ is the weight of the samples before drying and $m_{1}$ is the weight of the samples after drying.

\section{RESULTS AND DISCUSSION}

\section{Functional Groups}

The FTIR-ATR spectra of NR/ENR blends with and without DTBPIB are shown in Figure 1. The spectrum of blend NR/ENR: 100/0 [Figure 2(a)] shows strong peaks of unsaturated $\mathrm{C}=\mathrm{C}$ stretching and out-of-plane $\mathrm{C}-\mathrm{H}$ rocking at 1635 $\mathrm{cm}^{-1}$ and $1025 \mathrm{~cm}^{-1}$. On the other hand, medium peaks at $1450 \mathrm{~cm}^{-1}$ and $1375 \mathrm{~cm}^{-1}$ contribute to $-\mathrm{CH}_{2^{-}}$and $-\mathrm{CH}_{3^{-}}$bending. The intensity of peaks at $1635 \mathrm{~cm}^{-1}$ and $1025 \mathrm{~cm}^{-1}$ reduced drastically with crosslinking due to the radical reaction of DTBPIB with the unsaturated carbons of NR (P. Phinyocheep 2014). Peaks at $2935 \mathrm{~cm}^{-1}, 2864 \mathrm{~cm}^{-1}$ and $2840 \mathrm{~cm}^{-1}$ attributed to $\mathrm{C}-\mathrm{H}$ stretching and the peak at $830 \mathrm{~cm}-1$ indicating $\mathrm{C}-\mathrm{H}$ bending attached to unsaturated carbon (Kochthongrasamee, Prasassarakich \& Kiatkamjornwong 2006; Anancharungsuk et al. 2007). This proves that crosslinking has occurred in NR.

Figure 2(b) shows the NR/ENR: 0/100 spectrum with and without crosslinking, respectively. The peaks at $1110 \mathrm{~cm}^{-1}$ and 870 $\mathrm{cm}^{-1}$ indicate the epoxy ring and $\mathrm{C}-\mathrm{H}$ bending attached to the epoxy ring, (Mas Haris \& Raju 2014) whereas, strong peaks at $1499 \mathrm{~cm}^{-1}$ and $1377 \mathrm{~cm}^{-1}$ can be related to $-\mathrm{CH}_{2^{-}}$and $-\mathrm{CH}_{3^{-}}$ bending. A short, broad peak of $\mathrm{C}=\mathrm{C}$ stretching 

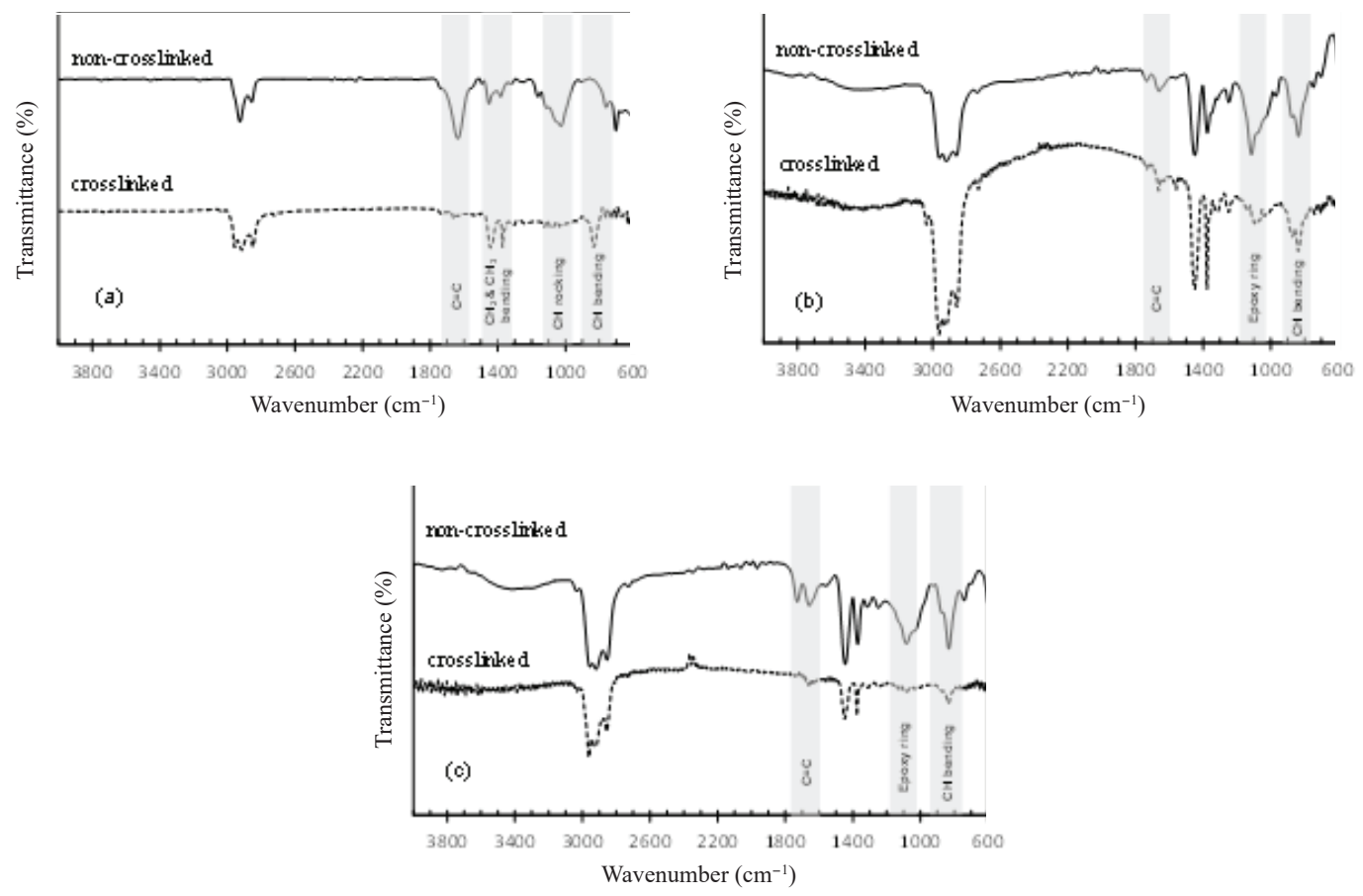

Figure 1. The FTIR spectra of NR/ENR blends with ratios of 100/0 (a), 0/100 (b) and 50/50 (c).

and $\mathrm{C}-\mathrm{H}$ bending attached to unsaturated carbon are also observed at $1663 \mathrm{~cm}^{-1}$ and $830 \mathrm{~cm}^{-1}$. The intensities at $1110 \mathrm{~cm}^{-1}$ and $870 \mathrm{~cm}^{-1}$ which are observed in NR/ENR:0/100 reduced after crosslinking, which might be due to the opening of the epoxy ring forming crosslink bridges. Subsequently, reduction in $\mathrm{C}=\mathrm{C}$ stretching and out-of-plane $\mathrm{C}$-H suggest that crosslinking has also occurred at the $\mathrm{C}=\mathrm{C}$ double bond.

Figure 1(c) shows the NR/ENR:50/50 spectrum with and without crosslinking. In the presence of crosslinking, the peaks of th epoxy ring at $1080 \mathrm{~cm}^{-1}$ and $\mathrm{C}-\mathrm{H}$ bending attached to the epoxy ring at $870 \mathrm{~cm}^{-1}$ were observed to reduce drastically. The same was observed for the $\mathrm{C}=\mathrm{C}$ stretching and $\mathrm{C}-\mathrm{H}$ bending attached to unsaturated carbon at peaks of $1653 \mathrm{~cm}^{-1}$ and $831 \mathrm{~cm}^{-1}$. From these results, it is evident that crosslinking has taken place in the NR/ ENR blends.

\section{Crosslinking Degree}

Figure 3 shows the effect of NR/ENR blend ratio on the gel content with and without DTBPIB.

The solvent (xylene) was observed to dissolve both NR and ENR, and their respective blends without crosslinking as the gel content obtained were almost $0 \%$. However, once crosslinked, the gel content increased. This proved the formation of three-dimensional networks between the chains in the rubbers. NR/ENR: 100/0 with crosslinking showed the highest gel content of $96 \%$ whereas NR/ ENR: 0/100 with crosslinking showed the least gel content of $75 \%$. The gel content between chains of NR was higher than between the chains of ENR and this could be due to the percentage of epoxy rings in the ENR forming less crosslinking bridges between the chains compared to the double bonds present in the isoprene of NR. 


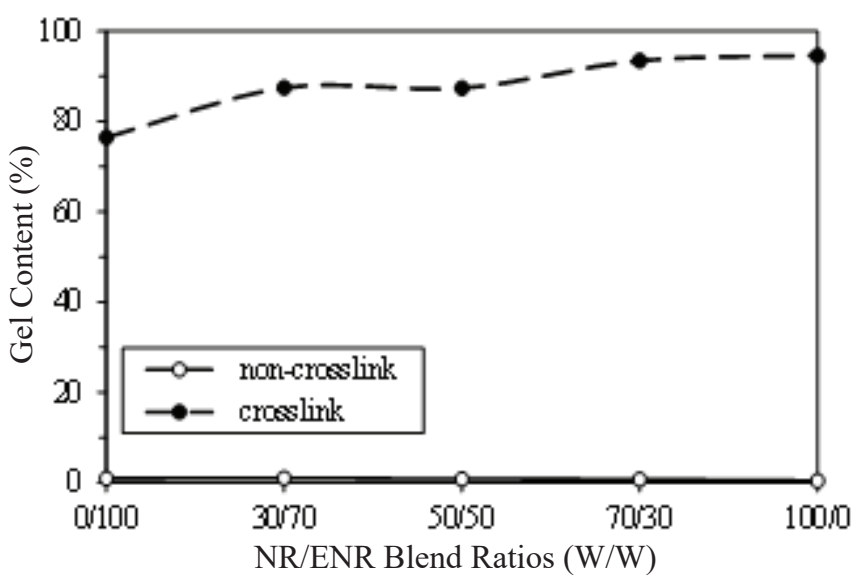

Figure 2. The percentage gel content of NR/ENR blends with and without DTBPIB.

\section{Tensile Properties}

Tensile modulus, tensile strength, and elongation at break of NR/ENR blends with and without DTBPIB are shown in Figure 3.

The tensile modulus [Figure 3(a)] and strength [Figure 3(b)] without crosslinking were independent of the blend ratios. This could be due to the absence of linkages between chains upon which application of minimal force resulted in the stretching of the films. On the other hand, elongation at break (EB) [Figure 3(c)] was reduced with increasing NR loading, due to the carbon-carbon double bonds that are stronger and more constraining upon stretching compared to the epoxy rings of ENR.

Upon the introduction of crosslinks, both tensile modulus at 300\% elongation (M300) and tensile strength increased for all blend ratios. The crosslinking results in stiffer and stronger blends due to the three-dimensional network formed which limited the molecular chain mobility of the polymer blend. Thus higher force was required to stretch the blend. It was also observed that when the NR loading increased, the blend showed higher tensile modulus and strength. This was because NR had more allylic carbon as compared to ENR. Therefore, with the higher amount of allylic carbon, a higher degree of crosslinking might be expected. This was consistent with the gel content results reported earlier.

The opposite was however observed for elongation at break. Although no significant changes were observed for the blends, changes were observed for the pure polymers with a reduction in EB for ENR (NR/ENR: 0/100) and an increase in the EB for NR (NR/ENR: 100/0). The poorer EB for ENR compared to NR was due to the three-dimensional network formation which limited molecular chain mobility. However, the scission of a much stiffer carbon double bond to form crosslinking could have increased the chain mobility in NR. The results were consistent with the FTIR-ATR and gel content reported earlier.

\section{Dynamic Mechanical Analysis}

The storage (E') and loss (E") moduli of the blends as a function of temperature in the presence of DTBPIB are shown in Figure 4. 

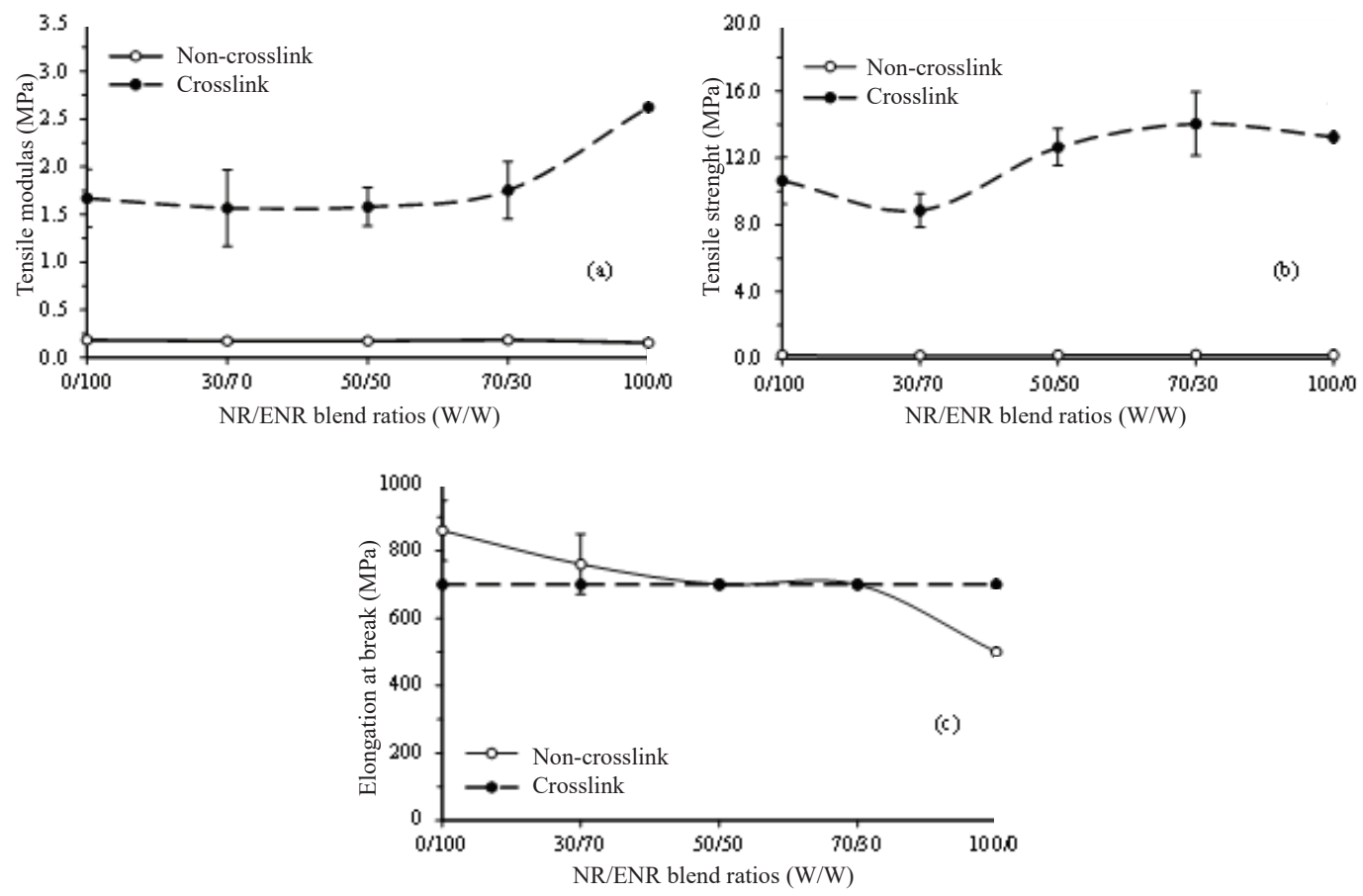

Figure 3. The tensile modulus at $300 \%$ elongation (a), tensile strength (b) and elongation at break (c) of NR/ENR blends.

In general, the changes in E' and E" are a direct representation of the intermolecular and intramolecular interactions between polymers. At low temperature, the moduli did not show much change as the deformation was primarily elastic due to the less molecular motion. As the temperature was increased, E' reduced reaching a minimum with no further changes. On the other hand, E" increased reaching a maximum before decreasing. The increase in E" was due to Brownian motion and stress relaxation acting together whereas the decrease in E" after that was due to the free movement of the molecular segments of the polymer (Sin et al. 2014). From the results in Figure 4, pure polymers (Figure 5 (a and e)) showed a single E" peak whereas two E" peaks were observed for the blends [Figure 5 (b, c and d)]. The two E" peaks show incompatibility between the polymers. However, as the NR content was increased, the distance between the two peaks reduced. In order to elucidate the results further, $\tan \delta$ was used (Figure 5).

Using the $\tan \delta$ value versus temperature plot in Figure 5(a), information on glass transition temperature ( $\mathrm{Tg}$ ) and damping were obtained. The $\mathrm{Tg}$ was indicated by the number of peaks and from Figure 6 (a), it was evident that both pure polymers (NR and ENR) showed single peaks indicating one $\mathrm{Tg}$ value whereas the blends showed two peaks indicating two Tg values. Damping, on the other hand, was observed from the $\tan \delta$ values. At their respective Tg, ENR showed $\tan \delta$ of 2 whereas NR showed $\tan \delta$ of 2.8. As the $\tan \delta$ was higher for NR, NR showed higher damping compared to ENR at Tg. Blending both polymers resulted in a significant reduction in damping as indicated by the reduced $\tan \delta$ 

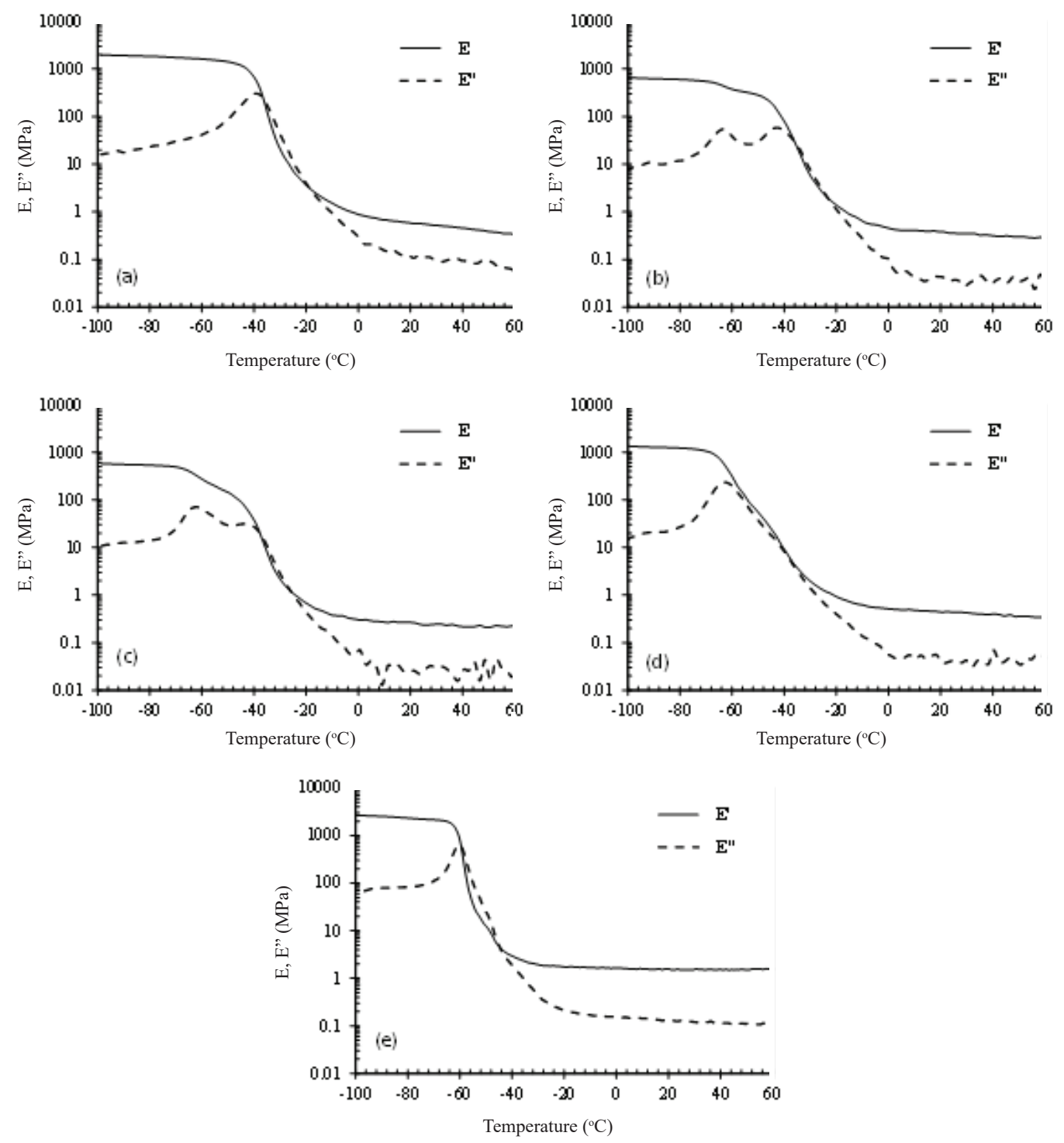

Figure 4. The effect of temperature on the storage (E') and loss (E") moduli of NR/ENR blend in the presence of DTBPIB for blend ratios of (a) 0/100, (b) 30/70, (c) 50/50, (d) 70/30, (e) 100/0.

values. Nevertheless, $\tan \delta$ values of the blends increased with increasing ENR content, and this was associated with the increase in interfacial bonding due to the increased crystallinity of blends (Chandra, Singh \& Gupta 1999; Sin et al. 2014).

At room temperature $\left(30^{\circ} \mathrm{C}\right)$, a change in the damping behaviour was observed for all blends (Figure 5(b). The damping of pure ENR
(ENR/NR:100/0) was double the damping of pure NR (ENR/NR:0/100). The blending of NR to ENR at all blend ratios also resulted in a reduction in damping as the $\tan \delta$ approached values of pure NR (in the range of 0.08 ). The higher damping of pure ENR was probably due to the presence of lesser allylic carbons and crosslinks compared to NR resulting in the higher molecular chain mobility. 


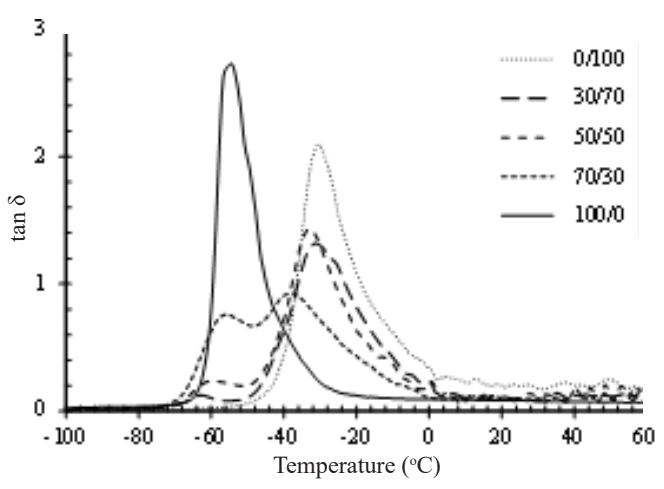

(a)

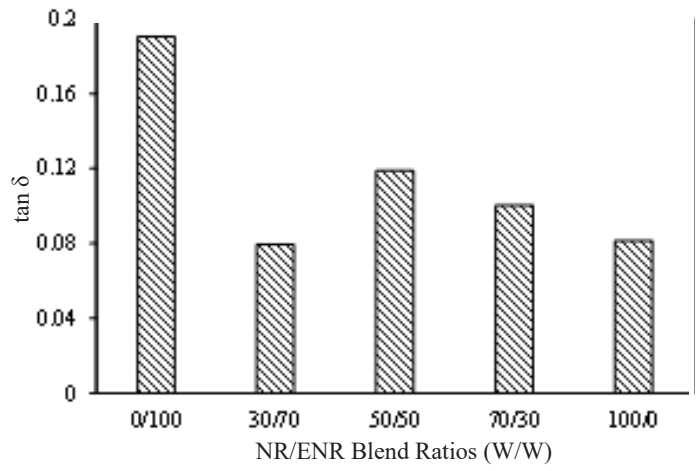

(b)

Figure 5. Tan $\delta$ of crosslinked NR/ENR blends as a function of temperature (a) and at $30 o C(b)$.

\section{Thermogravimetric Analysis}

The TGA and DTG curves of NR/ENR blends in the presence of DTBPIB are shown in Figure 6. From the thermograms, the information on the onset temperature of degradation and maximum decomposition temperature were obtained, and the results are summarised in Table 1 .

From Table 1, it is evident that blending NR with ENR improved the thermal stability of the blends as the onset temperature of NR/ ENR: 50/50 was higher than for pure NR and
ENR. However, the maximum decomposition temperature was slightly lower than pure ENR. In comparison to the NR, ENR showed an increase of $8^{\circ} \mathrm{C}$ and $10^{\circ} \mathrm{C}$ in onset and maximum decomposition temperature, respectively. NR exhibits low thermal stability and degrades in the presence of high temperature due to the $\mathrm{C}=\mathrm{C}$ in the backbone (Piya-Areetham, Rempel \& Prasassarakich 2014). This results in NR to be thermally less stable than ENR and blending NR with ENR enhanced the thermal properties of the blends.
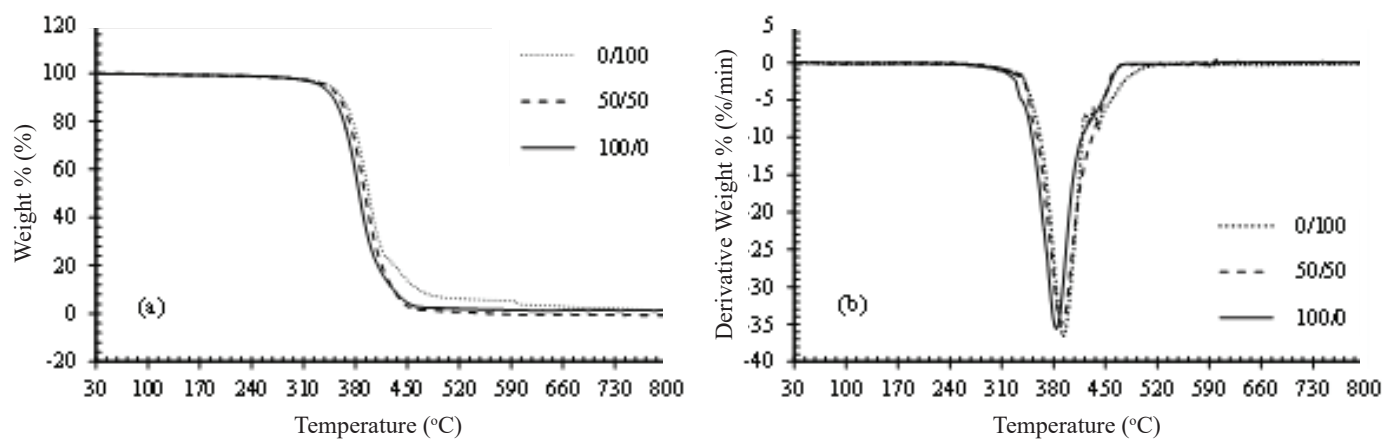

Figure 6. The TGA (a) and DTG spectra (b) of NR/ENR blends in the presence of DTBPIB. 
Table 1. Onset and maximum decomposition temperature of NR/ENR Blend with DTBPIB.

\begin{tabular}{c|cc}
\hline \multirow{2}{*}{ NR/ENR Ratio } & \multicolumn{2}{|c}{ Temperature $\left({ }^{\circ} \mathrm{C}\right)$} \\
& Onset & Maximum decomposition \\
\hline $0 / 100$ & 365.4 & 392.1 \\
$50 / 50$ & 367.2 & 390.3 \\
$100 / 0$ & 357.5 & 382.9 \\
\hline
\end{tabular}

\section{Water Absorptivity}

Figure 8 shows the water absorptivity by NR/ENR blends with and without DTBPIB, measured for 35 days. In comparison to blends without DTBPIB, the blends with DTBPIB [Figure $8(\mathrm{~b})$ ] showed a $50 \%$ reduction in water absorptivity. The DTBPIB forms a three-dimensional network which hinders the penetration of water molecules into the network, therefore reducing the water absorptivity of the blends (Abdelmouleh et al. 2007).

The highest water absorptivity was observed for NR/ENR:0/100 blend ratios, with and without DTBPIB. This was due to the high polarity of ENR which exhibited hydrophilic (polar) nature. A reducing trend in water absorptivity could be seen in the blends with increasing NR ratio. Ultimately NR/ENR blend ratio of 100/0 showed the least water absorptivity owing to the hydrophobic (nonpolar) structure of NR.

\section{CONCLUSION}

NR and ENR blends were successfully prepared by melt blending method. The FTIR-ATR showed crosslinking which occured not only in the pure polymers but also in the blends. As a result, the percentage gel content of the NR/ENR blends was increased with a higher degree of crosslinking observed for blends with increasing ratio of NR. Similarly, the tensile modulus at $300 \%$ elongation and tensile strength of NR/ ENR blends also increased with crosslinking. However, no changes were observed in the
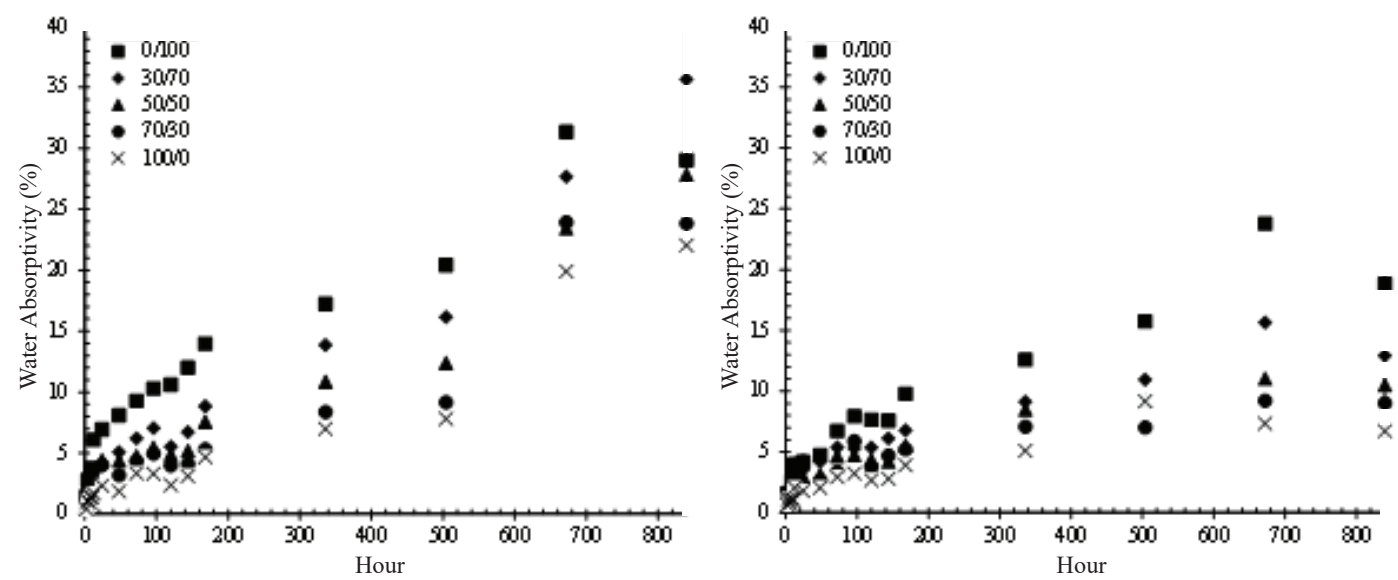

Figure 7. The water absorptivity of NR/ENR blends without DTBPIB (a) and with DTBPIB (b). 
elongation at break after crosslinking although a reduction in EB was observed in the absence of crosslinking with increasing NR loading. This was probably due to breaking of $\mathrm{C}=\mathrm{C}$ bonds to form $\mathrm{C}-\mathrm{C}$ linkages which were less constraining between NR polymers. Dynamic mechanical analysis revealed the blends which was immiscible due to the presence of two peaks which represented the individual polymers. At room temperature, ENR showed a more viscous behaviour which reduced with increasing NR loading. On the other hand, the thermal properties favoured ENR compared to $\mathrm{NR}$, as NR had more $\mathrm{C}=\mathrm{C}$ double bonds in the backbone which rendered a lower thermal stability. Therefore, blending ENR with NR improved the thermal properties of the NR/ ENR blend. In the absence of crosslinking, both polymers and their respective blends showed high water absorptivity with higher absorptivity favouring a higher ENR loading due to its polar nature. The introduction of polymer networks through crosslinking significantly reduced the water absorptivity.

Date of receipt: May 2017 Date of acceptance: October 2017

\section{REFERENCES}

Abdelmouleh, M. et al. 2007, 'Short naturalfibre reinforced polyethylene and natural rubber composites: Effect of silane coupling agents and fibres loading', Composites Science and Technology, vol. 67, no. 7-8, pp. 1627-1639.

Anancharungsuk, W. et al. 2007, 'Surface modification of natural rubber film by UVinduced graft copolymerization with methyl methacrylate', Journal of Applied Polymer Science, vol. 104, no. 4, pp. 2270-2276.
Arayapranee, W \& Rempel, GL 2007, 'Properties of NR / EPDM blends with or without methyl methacrylate-butadiene-styrene (MBS) as a Compatibilizer', International Journal of Materials \& Structural Reliability, vol. 5, no. 1, pp. 1-12.

Arroyo, M. et al. 2007, 'Morphology/behaviour relationship of nanocomposites based on natural rubber/epoxidized natural rubber blends', Composites Science and Technology, vol. 67, no. 7-8, pp. 1330-1339.

Benbettaïeb, N. et al. 2016, 'Tuning the functional properties of polysaccharideprotein bio-based edible films by chemical, enzymatic, and physical cross-linking', Comprehensive Reviews in Food Science and Food Safety, vol. 15, no. 4, pp. 739-752.

Chandra, R, Singh, S \& Gupta, K 1999, 'Damping studies in fiber-reinforced composites - a review', Composite Structures, vol. 46, no. 1, pp. 41-51.

De, D. et al. 2013, 'Reinforcing effect of reclaim rubber on natural rubber/polybutadiene rubber blends', Materials and Design. Elsevier Ltd, vol. 46, pp. 142-150.

Díaz, A, Katsarava, R \& Puiggalí, J 2014, 'Synthesis, properties and applications of biodegradable polymers derived from diols and dicarboxylic Acids: From Polyesters to poly(ester amide)s', International Journal of Molecular Sciences, vol. 15, no. 5, pp. 7064-7123.

Guo, B. et al. 2004, 'Thermoplastic elastomers derived from scrap rubber powder/LLDPE blend with LLDPE-graft-(epoxidized natural rubber) dual compatibilizer', Macromolecular Materials and Engineering, vol. 289 , no. 4 , pp. 360-367.

Gurunathan, T, Mohanty, S \& Nayak, SK 2015, 'A review of the recent developments in 
biocomposites based on natural fibres and their application perspectives', Composites Part A: Applied Science and Manufacturing. Elsevier Ltd, vol. 77, pp. 1-25.

Imbernon, L \& Norvez, S 2016, 'From landfilling to vitrimer chemistry in rubber life cycle', European Polymer Journal, Elsevier Ltd, vol. 82, pp. 347-376.

Ismail, H \& Nordin, RNA 2002, 'The comparison properties of recycle rubber powder, carbon black, and calcium carbonate filled natural rubber compounds', PolymerPlastics Technology and Engineering, vol. 41, no. 5, pp. 847-867.

Khimi, SR \& Pickering, KL 2015 , 'Comparison of dynamic properties of magnetorheological elastomers with existing antivibration rubbers', Composites Part B: Engineering, Elsevier Ltd, vol. 83, pp. 175-183.

Kochthongrasamee, T, Prasassarakich, P \& Kiatkamjornwong, S 2006, 'Effects of redox initiator on graft copolymerization of methyl methacrylate onto natural rubber', Journal of Applied Polymer Science, vol. 101, no. 4, pp. 2587-2601.

Mammadov, MS et al. 2012, 'Study of the structure and parameters of grid of hydrogenated butadiene nitrile rubber crosslinked with polymer peroxides', American Journal of Polymer Science, vol. 2 , no. 5, pp. 122-128.

Mas Haris, RHM \& Raju, G 2014 , 'Preparation and characterization of biopolymers comprising chitosan-graftedENR via acid-induced reaction of ENR 50 with chitosan', Express Polymer Letters, vol. 8, no. 2, pp. 85-94.

Mitragotri, S and Lahann, J 2009, 'Physical approaches to biomaterial design', Nature Materials, vol. 8, no. 1, pp. 15-23.
Notario, B, Pinto, J \& Rodriguez-Perez, MA 2016 'Nanoporous polymeric materials: A new class of materials with enhanced properties', Progress in Materials Science, Elsevier Ltd, vol. 78-79, pp. 93-139.

Pal, KV \& Panwar, JB 2017, 'Rubber blend nanocomposites', in Progress in Rubber Nanocomposites, 1st edn, eds S Thomas \& H. J. Maria, Woodhead Publishing.

Phinyocheep, P 2014, 'Chemical modification of natural rubber (NR) for improved performance', in Chemistry, Manufacture and Applications of Natural Rubber, Woodhead publishing, pp. 68-118.

Park, CY 2001, 'Cure characteristics and dynamic mechanical properties of acrylic rubber and epoxidized natural rubber blend', Journal of Industrial and Engineering Chemistry, vol. 7, no. 4, pp. 212-217.

Pedernera, M \& Sarmoria, C 1999, “An improved kinetic model for the peroxide initiated modification of polyethylene', Polymer Engineering, vol. 39, no. 10, pp. 2085-2095.

Piya-Areetham, P, Rempel, GL \& Prasassarakich, P 2014, 'Hydrogenated nanosized polyisoprene as a thermal and ozone stabilizer for natural rubber blends', Polymer Degradation and Stability, Elsevier Ltd, vol. 102, no. 1, pp. 112-121.

Rajasekar, R. et al. 2009, 'Development of nitrile butadiene rubber-nanoclay composites with epoxidized natural rubber as compatibilizer', Materials and Design, vol. 30, no. 9, pp. 3839-3845.

Ramesh, M 2016, 'Kenaf(Hibiscus cannabinus L.) fibre based bio-materials: A review on processing and properties', Progress in Materials Science, Elsevier Ltd, vol. 78-79, pp. 1-92. 
Sin, M. C. et al. 2014, "Viscoelastic, spectroscopic, and microscopic characterization of novel bio-based plasticized poly(vinyl chloride) compound', International Journal of Polymer Science, 2014, pp. 1-10.

Thitithammawong, A, Nakason, C, Sahakaro, K \& Noordermeer, JWM 2007, 'NR/PP thermoplastic vulcanizates: Selection of optimal peroxide type and concentration in relation to mixing conditions', Journal of Applied Polymer Science, vol. 106, no. 4, pp. 2204-2209.

Thitithammawong, A, Nakason, C, Sahakaro, K \& Noordermeer, JWM 2007, 'Thermoplastic vulcanizates based on epoxidized natural rubber/polypropylene blends: Selection of optimal peroxide type and concentration in relation to mixing conditions', European Polymer Journal, vol. 43, pp. 4008-4018.

Ulbricht, M 2006, 'Advanced functional polymer membranes', Polymer, vol. 47, no. 7, pp. 2217-2262.
Varghese, S, Karger-Kocsis, J \& Gatos, KG 2003, 'Melt compounded epoxidized natural rubber/layered silicate nanocomposites: structure-properties relationships', Polymer, vol. 44, no. 14, pp. 3977-3983.

Vinod, VS, Varghese, S \& Kuriakose, B 2002, 'Degradation behaviour of natural rubberaluminium powder composites: effect of heat, ozone and high energy radiation', Polymer Degradation and Stability, vol. 75, no. 3, pp. 405-412.

Wan Yunus, WMDZ. et al. 2013, 'Preparation and characterisation of crosslinked polycaprolactone and natural rubber (SMR CV 60) blends', Journal of Rubber Research, vol. 16 , no. 3 , pp. 147-161.

Wang, R. et al. 2016, 'Design, preparation and properties of bio-based elastomer composites aiming at engineering applications', Composites Science and Technology, Elsevier Ltd, vol. 133, pp. 136-156. 